\title{
Reforma psiquiátrica e inclusão social pelo trabalho
}

\author{
Psychiatric reform and social inclusion for work
}

Rúbia Cristina Rodrigues $^{1}$

Tanimar Pereira Coelho Marinho ${ }^{2}$

Patricia Amorim ${ }^{3}$

${ }^{1}$ Gerarte- Associação de Trabalho eProdução Solidária da SaúdeM ental. Rua 24, Qd H-11, Lote 7, Setor M arista. 74150-020 GoiâniaGO.

rubiacrodrigues@terra.com.br ${ }^{2}$ CAPS Beija Flor, Secretaria deSaúdedeGoiânia(GO).

${ }^{3}$ Programa Saudavelmente

- UnidadeSIASS (Atenção à

Saúde do Servidor),

UniversidadeFederal de

Goiás.
Abstract This study aims at understanding the link among labor, mental distress, and psychosocial rehab from the point of view of people with either mental disorders or psychoactive substance addiction, regarding the meaning of laboring in their lives. The study took place in Psychosocial Attention Centers(CAPS), in the city of Goiânia, State of Goiás, Brazil. There were eight participants of both genders, who would consider labor something important in their daily lives. Two different types of data wereused, as to mention, qualitative and exploratory methodology, by means of a focal group. The content analysis was used in evaluating the data provided. The results point at the importance of rescuing the history of labor among CAPS users. It is also of significance the profusion of meanings attributed to working by the users of mental health services. Labor proves to have an interface that is understood as a factor of protection and/or worsening of the condition of the subjects. The exclusion processes are re flected by the difficulty in obtaining social security/welfare benefits.

Key words Work, Labor, Psychiatric reform, Social inclusion
Resumo Este estudo busca compreender a relação entre trabalho, adoecimento mental e reabilitação psicossocial a partir da narrativa de pessoas portadoras de transtorno mental e usuárias de substâncias psicoativas sobre o sentido do trabalho. 0 estudo ocorreu em Centros de A tenção Psicossocial (CAPS) da cidade de Goiânia (GO), do qual participaram oito pessoas adultas e de ambos os sexos, que traziam o trabal ho como algo importante em suas vivências. U tiliza-se de metodologia qualitativa e exploratória, por meio da realização de grupo focal. Para o tratamento dos dados, utiliza-se a análisetemática. Os resultados apontam os sentidos do trabalho enquanto existencialização eidentidade social, autonomia e sociabilidade. $\mathrm{Na}$ interface com a saúde mental, 0 trabalho surge como protetor e/ ou adoecedor mental. Os processos de exclusão social dos participantes ocorrem através da dificuldade de acesso à seguridade social relacionada ao trabalho e ao preconceito social vivido na tentativa de ingresso ao mundo do trabalho. Enquanto possibilidade de (re) inserção social, o estudo mostrou que os CAPS têm dificuldades em propor alternativas de inclusão pelo trabalho, apesar da mel horia de vida promovida pelo acompanhamento psicossocial. Palavras-chave Trabalho, Reforma psiquiátrica, Inclusão social 
Introdução

Entre os desafios da reforma psiquiátrica brasileira, está a (re)inserção social das pessoas com transtorno mental na vida pública e coletiva, de forma que suas singularidades possam se expressar. $\mathrm{Na}$ (re) inserção social através do trabalho, os desafios correspondem ao modelo de produção capitalista contemporâneo, que exclui do mundo do trabal ho as pessoas consideradas inaptas e/ou improdutivas junto ao mercado.

H istoricamente, o pacto social que caracterizou o nascimento do capital ismo durantea passagem do século XVII ao século XVIII levou à expulsão de um grande contingente de pobres e doentes do mundo do trabal ho. $\mathrm{Na}$ Revolução France sa do século XVIII, na qual se instalou o slogan "Fraternidade, liberdade e igualdade" como signos de uma suposta universal ização dos direitos doshomens, o pacto social do capitalismo selecionou parcel as da população consideradas desajustadas socialmente. Esta população foi levada para as instituições beneficentes, sendo direcionadas posteriormente para o mercado de trabalho as pessoas em melhores condições de exercê-lo, como aproveitamento de mão de obra barata ${ }^{1}$.

No mesmo período, os loucos foram mantidos nas casas de internamento, em nome da proteção assistencial por parte do Estado. A partir destas instituições, os mesmos permaneceram confinados e excluídos até a instalação dos primeiros hospitais psiquiátricos, já no século XIX junto ao nascimento da psiquiatria. $N$ as instituições psiquiátricas, adotou-se junto aos internos a rotina de um trabalho sem valor subjetivo e material, com a finalidade de controlar os seus devaneios e domesticar o comportamento, por meio da ocupação do tempo. Este método é denominado de tratamento moral ${ }^{1}$.

Existe, portanto, uma intrínseca relação histórica na modernidade entre o desenvolvimento do capitalismo e a reclusão social da loucura. E, entre o mundo do trabal ho eo mundo da loucura, há uma problemática comum - a alienação. Para o trabalhador, a alienação ocorre em função do modelo de produção capitalista, com a perda do sentido do trabal ho ea exploração. Para os ditos loucos, a alienação advém da supremacia da razão cartesiana en quanto desenvolvimento das ciências modernas. Em ambos os casos, a alienação impacta o poder de contratualidade política, social erelacional, tanto do trabalhador, como das pessoas estigmatizadas de loucas.

Com o objetivo de promover a inclusão social através do trabalho junto às pessoas porta- doras de transtorno mental e usuárias de substâncias psicoativas, a política nacional de saúde mental, em conjunto com a política nacional de economia solidária, tem incentivado as iniciativas de geração de trabal ho e renda nas ações públicas intersetoriais. 0 trabalho como meio de inclusão social de pessoas portadoras de sofrimento mental se afirma enquanto um direito de cidadania e distinto das ações humanistas, ou mesmo assistenciais e terapêuticas.

É neste contexto de discussões sobre o trabaIho articulado à atenção psicossocial proposta pela reforma psiquiátrica brasileira que este estudo ocorreu, tendo por objetivos conhecer a história de trabalho dos participantes, identificar os impactos da vinculação dos mesmos a benefícios da seguridade social e sua relação com o trabalho, compreender o papel dos CAPS na geração de trabalho e renda a partir da visão dos participantes e contribuir para com o desenvolvimento de programas de geração de trabal ho e renda nas ações de saúde mental no município de Goiânia (GO).

\section{M etodologia}

A abordagem exploratória e qualitativa do processo saúde-doença na perspectiva do materialismo histórico adotada neste estudo buscou apreender o significado e as interpretações dos participantes da pesquisa quanto ao adoecimento mental eao processo de reabilitação psicossocial, tendo o trabal ho como o mediador das discussões. 0 estudo foi realizado em 2005 em Centros de Atenção Psicossocial (CAPS) que atendem pessoas portadoras de transtorno mental e decorrente do uso e dependência de substâncias psicoativas da cidade de Goiânia (GO). Participaram do estudo oito indivíduos adultos, de ambos os sexos ( $Q$ uadro 1), provenientes de quatro CAPS e que respondiam aos seguintes critérios: (1) ter manifestado o desejo por trabaIho durante a reabilitação psicossocial; (2) possuir história de adoecimento mental relacionado ao ambiente de trabalho; (3) estar em condições psíquicas e emocionais para participar da pesquisa; (4) concordância com o termo de consentimento livre eesclarecido. Os dados foram coletados através de consulta em prontuários, entrevistas semiestruturadas e realização de grupo focal. Um rotei ro para a orientação das questões a serem abordadas no grupo focal foi previamente elaborado com base na literatura e na experiência empírica das pesquisadoras. 0 grupo 
focal foi gravado e posteriormente os conteúdos foram transcritos. Para análise dos dados, optou-se pela utilização da análise temática, apropriada ao estudo em saúde. Conforme M inayo ${ }^{2}$, nessa técnica, os temas que surgem na pesquisa revelam valores e comportamentos presentes no discurso. Através da leitura do material transcrito, identificaram-se as categorias de análises temáticas, identificando a representatividade das falas dos partici pantes conforme os objetivos do estudo. A pesquisa foi aprovada pelo Comitê de Ética em Pesquisa da Universidade Católica de Goiás (UCG). Os participantes foram identificados pelas letras do alfabeto, de $\mathrm{A} \mathrm{a} \mathrm{H}$.

\section{Apresentação ediscussão dos resultados}

Para apresentação e discussão dos resultados, os dados foram organizados nos seguintes eixos temáticos: (1) História detrabalho, (2) Os sentidos do trabalho; (3) Trabalho, saúde e adoecimento mental; (4) Adoecimento mental eseguridadeso- cial; (5) Adoecimento mental, preconceito e exclusão do trabalho e (6) Reabilitação psicossocial e inclusão social pelo trabalho (Quadro 2).

\section{História de trabalho}

0 estudo identificou que os sujeitos pesquisados iniciaram-se na atividade laboral na préadolescência (a partir dos dez anos de idade), sobre influência da necessidade econômica de suas famílias. Desenvolveram trabalhos com pouca qualificação profissional, baixa remuneração e com alta rotatividade nos empregos e trabalhos (Quadro 3).

\section{Os sentidos do trabalho}

Os sentidos do trabalho foram atribuídos pelos participantes quanto à:

(1) Conquista deindependência eautonomia, enquanto possibilidade deindepen dência econômica e moral da família. M arx ${ }^{3}$ já dizia que o homem independente só o é quando a si mesmo

Quadro 1. Características sociodemográficas e clínicas dos participantes do estudo.

\begin{tabular}{|c|c|c|c|}
\hline \multicolumn{4}{|c|}{ Usuários de CAPS II e AD de Goiânia que participaram do estudo ( $\mathrm{n}=8$ ) } \\
\hline \multicolumn{2}{|l|}{ 1. Características sociodemográficas } & \multicolumn{2}{|l|}{ 2. Características clínicas } \\
\hline Sexo & & Duração da doença (anos) & \\
\hline Feminino & 4 & $0-5$ & 2 \\
\hline M asculino & 4 & $6-10$ & 1 \\
\hline Idade (média) & 34 anos & $11-15$ & 2 \\
\hline Estado civil & & $16-20$ & 1 \\
\hline Solteiro & 5 & $21-25$ & 1 \\
\hline Casado & 1 & $26-30$ & 1 \\
\hline Separado / viúvo & 2 & Diagnóstico (CID-10)* & \\
\hline Escolaridade & & Esquizofrenia & 4 \\
\hline Ensino fundamental & 4 & Transtorno Bipolar & 2 \\
\hline Ensino M édio & 4 & Transtorno do Pânico & 1 \\
\hline Superior & 0 & Dependência de Substâncias Psicoativas & 1 \\
\hline Renda & & Internações prévias & \\
\hline 1 a 2 salários mínimos & 7 & Sim & 8 \\
\hline > 2 salários mínimos & 1 & Não & 0 \\
\hline Situação atual de trabalho & & U so atual de psicofármacos & \\
\hline Formal & 3 & Sim & 8 \\
\hline Informal & 3 & Não & 0 \\
\hline Desempregado & 2 & & \\
\hline Benefício da Prestação Continuada (BPC) & & & \\
\hline Sim & 2 & & \\
\hline Não & 6 & & \\
\hline Auxílio-doença (INSS) & & & \\
\hline Sim & 2 & & \\
\hline Não & 6 & & \\
\hline
\end{tabular}

* Classificação Internacional de Doenças - CID $10^{20}$. 
Quadro 2. Apresentação e discussão dos resultados.

\begin{tabular}{|c|c|}
\hline Eixo temático & Conteúdos abordados \\
\hline $\begin{array}{l}\text { I. História de trabalho dos } \\
\text { participantes }\end{array}$ & $\begin{array}{l}\text { - Inserção precoce no mundo do trabalho } \\
\text { - Realização de atividades de baixa qualificação profissional } \\
\text { - Baixa remuneração } \\
\text { - Rotatividade em empregos e trabalhos diversificados } \\
\text {. Trabalho motivado pela necessidade econômica da família }\end{array}$ \\
\hline II. Os sentidos do trabalho & $\begin{array}{l}\text { Conquista de independência e autonomia } \\
\text { Existência social e identidade } \\
\text { M eio de sociabilidade }\end{array}$ \\
\hline $\begin{array}{l}\text { III. Trabalho, saúde } \\
\text { e adoecimento mental }\end{array}$ & $\begin{array}{l}\text { O trabalho como fator de proteção a saúde } \\
\text { O trabalho como desencadeador de adoecimento mental } \\
\text {. } 0 \text { trabalho como compreensão e explicação do adoecimento mental } \\
\text {. Supremacia das avaliações biológicas para o ingresso no mundo do } \\
\text { trabalho } \\
\text {. As condições de trabalho como potencializador de adoecimento mental } \\
\text {. Rompimento com o mundo do trabalho }\end{array}$ \\
\hline $\begin{array}{l}\text { IV. Adoecimento mental e } \\
\text { dificuldade de acesso à } \\
\text { seguridade social }\end{array}$ & $\begin{array}{l}\text { Violação de direitos } \\
\text {. N egação do sujeito e de seu sofrimento na perícia do Instituto Nacional } \\
\text { de Seguridade Social } \\
\text {. Paradoxo do Benefício de Prestação Continua da Lei Orgânica da } \\
\text { Assistência Social, quanto à exigência de curatela/tutela para o acesso ao } \\
\text { direito social. }\end{array}$ \\
\hline $\begin{array}{l}\text { V. Adoecimento mental, } \\
\text { preconceito e exclusão do } \\
\text { trabalho }\end{array}$ & $\begin{array}{l}\text { N Não acesso a cursos de qualificação profissional } \\
\text { Perda da confiança no ambiente de trabalho no uso de álcool } \\
\text {. Rebaixamento na função laboral } \\
\text {. O auto preconceito }\end{array}$ \\
\hline $\begin{array}{l}\text { VI. Reabilitação psicossocial } \\
\text { e inclusão social pelo } \\
\text { trabalho }\end{array}$ & $\begin{array}{l}\text { Papel dos Centros de Atenção Psicossocial (CAPS) } \\
\text { Busca subjetiva de autocontrole na reabilitação psicossocial, para } \\
\text { remissão do quadro clínico sintomático. }\end{array}$ \\
\hline
\end{tabular}

* Classificação Internacional de Doenças - CID $10^{20}$.

deve a sua existência. Do contrário, o homem é um ser que não é dono de si. A produção de recursos financeiros promove 0 autossustento e, consequentemente, maior autonomia. Isso demonstra a importância da superação do fardo que muitas vezes expressam as famílias de pessoas com transtornos mentais para com seus entes, principalmente as de baixa renda. Conforme Rosa ${ }^{4}$, o que se verifica na maior parte do núcleo familiar são "[...] conflitos intrafamiliares entre as pessoas geradoras de renda e aqueles dependentes de cuidados [...]". 0 peso da situação financeira nas famílias com portadores de transtorno mental compõe a história da psiquiatria, na qual a utilização das internações psiquiátricas representa a busca de suporteà emergência socio- econômica por famílias de baixa renda, para alívio da carga financeira. Outra situação relativa à não autonomia econômica de pessoas portadoras de transtorno mental quando inseridas no contexto da instituição hospitalar diz respeito à administração estabelecida pelo hospital, em relação aos poucos recursos financeiros dos internos. Conforme Ferraz ${ }^{5}$, em seus estudos sobre a gestão de recursos pessoais de pacientes, o manejo do dinheiro dos usuários ocorresem nenhuma participação dos mesmos. 0 autor atribui este fato à "crença geral de que isolados e assistidos os pacientes não precisam de dinheiro".

A conquista da independência financeira pelos sujeitos pode reverter o quadro acima citado e levar à inclusão na família. Quando o sujeito 
Quadro 3. História de trabalho dos participantes e vinculação à seguridade social.

\begin{tabular}{|c|c|c|c|}
\hline Sujeito & Experiências & $\begin{array}{l}\text { Inserção atual } \\
\text { no trabalho }\end{array}$ & $\begin{array}{l}\text { Inserção na } \\
\text { Seguridade Social }\end{array}$ \\
\hline A & $\begin{array}{l}\text { "Caseiro de casa” (cozinhava, lavava, } \\
\text { passava, tratava de porco, de galinha), } \\
\text { cabeleireiro, tarólogo, quiromante e } \\
\text { dançarino (danças contemporâneas). }\end{array}$ & $\begin{array}{l}\text { Trabalho autônomo como } \\
\text { cabeleireiro }\end{array}$ & $\begin{array}{l}\text { Inserido no Benefício de } \\
\text { Prestação Continuada } \\
\text { da Assistência Social - } \\
\text { BPC/LOAS }\end{array}$ \\
\hline B & $\begin{array}{l}\text { Comerciante, prestador de serviços na } \\
\text { M etrobus, ajudante em construção civil. }\end{array}$ & $\begin{array}{l}\text { M ercado formal - empregado } \\
\text { em supermercado }\end{array}$ & $\begin{array}{l}\text { Vínculo previdenciário - } \\
\text { contribuinte INSS }\end{array}$ \\
\hline $\mathrm{C}$ & $\begin{array}{l}\text { Auxiliar de escritório em confecção e na } \\
\text { área de informática nos Correios, porteiro } \\
\text { de colégio, motorista, vendedor de livros, } \\
\text { pesquisador do IPLAN e ajudante em Pit } \\
\text { Dog. }\end{array}$ & Desocupado & $\begin{array}{l}\text { Inserido no Benefício } \\
\text { de Prestação } \\
\text { Continuada da } \\
\text { Assistência Social - } \\
\text { BPC/LOAS }\end{array}$ \\
\hline $\mathrm{D}$ & $\begin{array}{l}\text { Doméstica, recepcionista em } \\
\text { supermercado, estagiária de enfermagem } \\
\text { (auxiliar) em hospital público. }\end{array}$ & $\begin{array}{l}\text { Vendedora de picolé, } \\
\text { prestadora de serviços }\end{array}$ & Sem vínculo \\
\hline $\mathrm{E}$ & Laboratorista, costureira, bordadeira & $\begin{array}{l}\text { Costureira, vendedora } \\
\text { autônoma em feira livre }\end{array}$ & Sem vínculo \\
\hline $\mathrm{F}$ & $\begin{array}{l}\text { Auxiliar administrativo em comércio da } \\
\text { família e técnica em informática }\end{array}$ & $\begin{array}{l}\text { Mercado formal -funcionária } \\
\text { pública da Secretaria de Saúde } \\
\text { - Pará }\end{array}$ & $\begin{array}{l}\text { Auxílio-doença/ } \\
\text { IN SS }\end{array}$ \\
\hline G & Sapateiro, lavador de ônibus na I tatur & Desocupado & Sem vínculo \\
\hline $\mathrm{H}$ & Técnica de enfermagem & $\begin{array}{l}\text { M ercado formal - empregada } \\
\text { em hospital da rede privada }\end{array}$ & $\begin{array}{l}\text { Auxílio-doença/ } \\
\text { IN SS }\end{array}$ \\
\hline
\end{tabular}

sabe que pode contribuir financeiramente para com as despesas domésticas e para com o cuidado, expressa o sentimento de ser útil, conforme os relatos: Sempre tive o pensamento de nunca ser dependente. Queeu tenho quefazer algo para ajudar em casa. (B)

Eu sempre tive vontade de ser independente e procurar fazer o contrário. Não ser ajudado, mas sim ajudar. (C)

0 trabalho como independência e autonomia foi relatado através dos projetos de alguns participantes da pesquisa de ter o próprio negócio, buscando sair da situação de desocupado. Ter o próprio negócio pode representar várias situações, como a saída da relação assalariada entre patrão e empregado, a manutenção da vinculação a benefícios assistenciais e pela pessoa vir a fazer al go dentro das possibilidades, sem a obrigação de responder às exigências fora do alcance do sujeito.

(2) O sentido do trabalho como existência social eidentidade, a qual está muito presentena forma como nos apresentamos ou como procu- ramos identificar o outro, inclusive quanto à posição de classe social. São comuns as perguntas “Qual seu nome?", "Onde você mora?", “Em que você trabalha?"

A centralidade da atividade produtiva do homem pelo trabalho é fato histórico que vem demarcando o desenvolvimento das relações sociais e da organização política nas diferentes sociedades. Desde a pré-história, o homem intervém e transforma a natureza, de forma que o desenvolvimento da subjetividade não existe separado das relações objetivas entre os homens, relações estas mediadas pelo trabal ho no qual os homens se constituem socialmente ${ }^{3}$. Conforme Silva FiIho ${ }^{6}$, o trabalho possui um vetor relevante de identidadepor representar o pertencimento a uma comunidade, no qual o indivíduo passa boa parte do seu tempo, bem como almeja objetivos na vida por meio do trabalho. Verificamos esta dimensão conforme as falas a seguir: Porque trabalho preenchia minha vida, preenchia o vazio que eu sentia eajudava a mesentir gente. Sem trabalho não tem importância na vida. (E) 
Porque eu acho que eu sem trabalho não sou ninguém. ( $F$ )

(3) 0 sentido do trabalho como meio de sociabilidadeatribuído pelos participantes, importante para a noção de rede em saúde mental, na qual a ação assistencial não pode se desvincular da dimensão da vida relacional fora dos serviços. A esfera da casa, da comunidade através do círculo de vizinhanças, amigos, lazer, entre outros, o suporte mútuo em substituição ao isolamento social que provoca o adoecimento, se ne gligenciados na atenção psicossocial, reproduzem a dependência institucional. N estecampo, 0 trabalho tem um caráter positivo, por favorecer a ampliação da esfera da vida doméstica junto das pessoas portadoras de transtorno mental para a vida pública. Para os sujeitos da pesquisa, o trabal ho tem o sentido de vetor dos encontros sociais e da circulação pela cidade: 0 fato da gente sair de casa, vocêconversar com pessoas diferentes, ver o trânsito na rua, eu acho isso gostoso. (C)

Trabalho, saúde e adoecimento mental

Explorando a relação entre trabalho, saúde e adoecimento mental, o estudo constatou dois fatores do trabalho moderno que interagiram e impactaram o percurso de cada sujeito, sendo o trabal ho como protetor do adoecimento mental e como causador do adoecimento. Esta relação entre trabalho e adoecimento mental pode ser examinada tanto na dimensão subjetiva, quanto na dimensão da realidade objetiva dos participantes.

Em um primeiro momento da dimensão subjetiva dos participantes, o trabalho é interpretado como um recurso importante de proteção às recaídas e às crises, possível através da ocupação da mente e do tempo. Os participantes narram a necessidade de estarem em atividades, a fim de substituírem preocupações ou pensamentos negativos. Como exemplo, os participantes lembram os ditos populares como, "mente vazia, oficina do diabo". Em um caso particular, o trabalho sempre teve lugar central e serviu, na medida em que pôde ser realizado, como um dispositivo que favoreceu a resolução das crises. Permitiu, assim, a redução das atividades no CAPS em função do novo compromisso do sujeito para com o seu trabalho. Seguem-se os relatos:

Q uando a gente trabalha, a gente esquece das coisas, ajuda a fazer tratamento. (B)

Então, preenchendo o meu tempo com trabaIho, isso faz com que as crises não sejam periodicamente. (A)
No segundo momento da compreensão subjetiva por parte de al guns participantes, o estudo identificou o trabalho como uma forma de compreender e explicar 0 adoecimento mental. Alguns participantes atribuem como causa do adoecimento mental o estresse do trabalho, conforme relato abaixo:

Foi assim essa doença; só deu estresse que hoje éfalado em esquizofrenia. D eu mais devido ao trabalho. Foi trabalho esgotativo. (B)

$\mathrm{Na}$ dimensão da realidade objetiva da relação entre trabalho, saúde eadoecimento mental, os participantes discorrem sobre a seleção para o ingresso no trabalho e as condições para exercêlo. No primeiro caso, foram criticadas as avaliações para o ingresso no mundo do trabalho, que consideram a presença de doença mental como indicador de incapacitação para o trabaIho. São comuns o examepsicotécnico eo exame psiquiátrico, que buscam a descoberta de patologias, em detrimento das experiências dos indivíduos. Jardim ${ }^{7}$ e Ramos et al. ${ }^{8}$ abordam a interface entre doença e trabalho, apontando que há um privilégio da dimensão biológica em detrimento da dimensão histórica e sociológica, que envolve o fator adoecimento no mundo do trabalho. Para os autores, "a história de trabalho é um dos aspectos pouco valorizados nas entrevistas médicas, inclusive as psiquiátricas" ${ }^{\text {. }}$.

$\mathrm{N}$ as condições de trabalho, surge a questão degênero traduzida na sobrecarga física eemocional da mulher, a exemplo de uma trabalhadora da rede hospitalar privada que teve como fator agravante do seu adoecimento mental o processo de trabalho. 0 ambiente de trabalho caracterizava-sepor ritmo intenso, em escal as com poucos recursos humanos para atender a demanda. Dado à subordinação sociotécnica do trabalho de auxiliar de enfermagem em relação ao enfermeiro e ao médico, a trabalhadora optou por não expressar o seu sofrimento, por medo de perder a confiança especialmentedo médico que Ihe repassava serviço eser demitida do emprego. No relato da participante, percebe-se os traços constitutivos do trabalho como potencializador desofrimento psíquico. Em outra situação, o trabalho feminino realizado na rua convive com a dura competição por espaço físico, disputado inclusive pela forçafísica masculina edifíceiscondições de trabal ho, como o sol e a sintomatologia física, em que pesam cansaço e desconforto diário.

No processo de adoecimento mental dos participantes, o que se verifica é o rompimento com o mundo do trabalho, devido às interna- 
ções psiquiátricas constantes, levando a rupturas e dificuldades de ( $r$ e) inserção no trabal ho por parte das pessoas portadoras de transtorno mental e usuárias de substâncias psicoativas.

\section{Adoecimento mental}

e dificuldade de acesso à seguridade social

0 presente estudo identificou a relação dos participantes com as áreas da Previdência Social por meio do auxílio-doença e da assistência social através do Benefício de Prestação Continuada, ambos operacionalizados pelo Instituto $\mathrm{N}$ acional de Seguro Social (INSS). A análise centrou-se em dois aspectos principais desta relação: a perícia médica e as implicações do amparo assistencial.

Em relação à perícia médica, esta faz parte de um conjunto de procedimentos técnico-normativos e administrativos do INSS. Como instrumento de avaliação, éutilizada para definir a capacidade laboral ou não do requerente ao benefício pretendido, tanto para o auxílio previdenciário como para o amparo assistencial. Dentre os participantes da pesquisa, dois estão afastados do trabalho por auxílio-doença e dois possuem - Benefício de Prestação Continuada da Assistência Social. Para os entrevistados, a perícia médica é vista como o poder máximo da avaliação exercida na instituição. A problemática relativa à perícia médica mencionada pelos participantes foi:

a) a relação burocrática do avaliador durante a entrevista: Eles não lêem o relatório. Eles só pegam a identidade; trouxe 0 atestado? Eles ol ham apenas o código do CID, só. Aí passa lá fora e pega os papéis. Você não sabe se recebeu alta ou se você não recebeu. $(\mathrm{H})$

b) do sentimento de impotência evulnerabilidade do beneficiário frente ao avaliador: Tanto queestou pensando, a minha licença termina amanhã, entendeu, e assim eu vou ter que fazer uma nova perícia. Isso está mexendo com a minha cabeça, eu estou num dilema. (F)

c) incompatibilidade entre perito econdições subjetivas do beneficiário, gerando angústia etensão, fator detensão emocional: N ão estou mesentindo $100 \%$ ainda, eu acho que estou uns $70 \%$. Ainda faltam $30 \%$; então, enquanto eu não me sentir $100 \%$, é meio perigoso. $(F)$

Diante do quadro burocrático do INSS, constituído muitas vezes por arbitrariedades no processo pericial, que limitam 0 acesso da população que demandam os serviços, caracterizando violação de direitos, é que pessoas com transtorno mental desenvolvem estratégias de enfrenta- mento como as demonstradas por um sujeito pesquisado para conseguir o Benefício dePrestação Continuada da Assistência Social, ao encenar a loucura durantea conversa com o perito, explicitado na fala de um participante da pesquisa: Com ele tive que fazer que fosse uma pessoa assim, totalmente doente mesmo, esquizofrênico, uma pessoa esquisita. Tirei os óculos, eu quero te ver melhor. U ma palavra quedurava pelo menos cinco minutos, eu falava em torno assim, de uns quinze minutos. Eu dificultava as coisas; eu acho quevenci pelo cansaço. Ele viu que não tirava nada do que ele queria mesmo. Pra falar a verdade, eu menti todas elas; menti porque, você sabe, se você tenta por bem, a vida toda não consegue, vocêtem outro recurso. É, foi uma coisa assim, digamos irônica, pra falar a verdade. Eu fiz muito teatro aqui no CAPS e por isso que foi uma forma muito, muito esplendorosa. (A)

Em estudo sobre o manual do médico-perito da Previdência Social, Jardim ${ }^{9}$ questiona a idéia de imparcialidade do médico perito, ponderando que os mesmos "[...] devem julgar situações com base numa sólida formação clínica, sem se deixar influenciar por fatores extra-doença como problemas sociais, desemprego, apelos, etc." [grifos do autor].

Outra crítica apontada por Jardim ${ }^{9}$ ao manual do médico-perito é da simulação, considerada como " [...] eventos na militância do médico-perito que não podem ser esquecidos no trabalho diário". Em Castel ${ }^{10}$, a perícia expressa a própria definição de poder efaz parteda racionalização da sociedade ocidental. 0 médico nesta área e, acrescentamos, qualquer outro servidor da burocracia, exerce o papel deárbitro. Segundo o autor, "através de um raciocínio de estilo técnico ou científico toma-se uma decisão que diz respeito a um terceiro e que irá selar seu destino"10.

Em relação ao Benefício de Prestação Continuada da Assistência Social (BPC/LOAS), o estudo identificou, além da dificuldade deacesso, 0 estímulo à busca de curatela/tutelas para sua concessão.

O Benefício de Prestação Continuada (BPC), instituído pela Lei O rgânica da Assi stência Social (LOAS), consistena garantia deum salário mínimo mensal à pessoa portadora de deficiência e ao idoso com 67 anos ou mais e que comprove não possuir meios de prover a própria manutenção e nem têla provida por sua família.

O BPC/LOAS foi regulamentado pelo Decreto den $01.744^{11} \mathrm{em} \mathrm{08/10/1995} \mathrm{e,} \mathrm{segundo} 0$ arti-

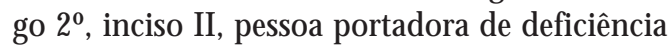
incapacitada para a vida independente e para o 
trabalho é aquela que, em razão de anomalias ou lesões irreversíveis de natureza hereditária, congênita ou adquirida, esteja impedida de desempenhar as atividades de vida diária e de trabaIhar. Dentre as situações em que pessoas portadoras de deficiência terão direito ao benefício, desde que preenchidas as demais condições citadas inicialmente, constam as alterações das faculdades mentais com grave perturbação da vida orgânica e social (síndrome equadros de origem neurológica e/ou psiquiátrica).

Junto ao critério de incapacidade para o trabalho, constata-se que no formulário do BPC denominado Requerimento deAmparo Assistencial - Lei 8.742/93' deve acompanhar o requerimento, está o pedido de termo de curatela/tutela. 0 que se verifica é que, contrariando os objetivos de cidadania, pessoas com transtorno mental são induzidas a abrir mão de seu direito civil sem saber o que isto representa, através de curatelas e tutelas, para, paradoxalmente, ter acesso a um direito social.

A não apresentação de um curador por parte do requerente invalida todo o processo de avaliação e concessão do BPC, mesmo que os demais critérios exigidos sejam respondidos, como demonstra uma participante: Eu tentei um processo com três atestados psiquiátricos no Serviço Social, el es mandam arrumar uma pessoa. Por causa que minha mãe e meu pai já morreu, só tenho minha cunhada. M inha irmã écasada, as duas eu não sei 0 endereço. É difícil. Eles querem um parente, um tio, um primo, para poder me encostar. Eu desperdicei três atestados. Eles não encostam. 0 médico nem olhou na minha cara. 0 da assistente social ficou em branco. (D)

H ouve mudanças no decreto original do BPC/ LOAS através de várias medidas provisórias (MP), ocorridas entre 1997 e 1998, sendo quea M P den$1473-34^{13}$ alterou a forma da avaliação. 0 decreto original autorizava que instituições parceiras que trabalhavam com reabilitação realizassem os laudos médico, social epsicológico, através de equipe multiprofissional que geralmente assistia as pessoas por elas encaminhadas ao INSS. A referida medida provisória instituiu que somenteo Setor de Perícia M édica do INSS poderia realizar a perícia eemitir o laudo médico. A M P deno 1473 $34^{13}$ foi alterada pela lei de $n=9.720 / 98^{14}$, quecondensou as inúmeras alterações realizadas na Lei Orgânica da Assistência Social, pelo Presidenteda República na ocasião. Tais alterações promoveram, de modo geral, restrições significativas no acesso de possíveis beneficiários do BPC/LOAS, bem como no exercício do controlesocial da soci- edade civil organizada junto às diretrizes da política de Assistência Social.

O M ovimento Nacional da Luta Antimanicomial, composto por trabalhadores, usuários, familiares, gestores e entidades de defesa de direitos, tem levantado a preocupação com 0 aumento dos requerimentos decuratelas/tutelasem função do BPC/LOAS. Conforme dados do M inistério do Desenvolvimento Social e Combateà Fome/Secretaria Nacional de Assistência Social, até 0 mês de junho de 2005, são 12.000 .300 de beneficiários totais, entre deficientes, idosos, renais crônicos, pessoas com transtorno mental e outros. Destes, 156.000 .00 são curatelados, re presentado $12 \%$ dos beneficiários; 1.166 .682 são pessoas portadoras de deficiência e curateladas e 64.035 são curatelados por transtorno mental, representando 5,5\% dos beneficiários totais $s^{15}$.

A fim de discutir as questões de curatela/tutelas no âmbito do benefício assistencial, realizouse, no ano de 2005, na Câmara dos Deputados Federais, a segunda etapa de um seminário sobre a banalização da interdição judicial no Brasil. H ouvea perspectiva de que, com diálogo entreos órgãos competentes, poder-se iam realizar alterações breves na prática da avaliação pericial, dentre outros. Os representantes governamentais assumiram al guns encaminhamentos, dentre el es 0 envio aos postos do INSS de um ato normativo sobre a não obrigatoriedade do termo curatela/ tutela, pautando-se no Decreto de $\mathrm{n} 01.744 / 95^{11}$, do qual não consta tal exigência (em 13 defevereiro de 2006, o Presidente Luis Inácio Lula da Silva assinou o Decreto $n=5.699^{16}$, revogando as exigências do termo de curatela para os casos de aposentadoria por invalidez decorrente de doença mental, aplicado também ao benefício de prestação continuada concedido pela LOAS). Avaliouse, por ocasião do seminário, a necessidade de incluir as especificidades da saúde mental no BPC, uma vez que este amparo assistencial destaca as demandas dos portadores de deficiências e dos idosos, segmentos protagonistas da conquista da Lei Orgânica da Assistência Social.

A revisão sobre curatelas/tutelas em saúde mental faz parte dos objetivos da reforma psiquiátrica brasileira, de reflexões críticas da relação histórica entre a psiquiatria e a jurisprudência. 0 objetivo é a revisão do julgamento que a justiça pública faz das pessoas portadoras de transtorno mental em seus códigos, legislações e nas práticas da psiquiatria forense. Frequentemente, não se reconhece o portador de transtorno mental enquanto um sujeito de direitos, levando, assim, às práticas automatizadas da in- 
terdição por curatelas e tutelas. A superação da curatela/tutela é também desafio à Assistência Social, devido à utilização indevida do clientelismo. Estabelece, nestes casos, uma relação tuteladora dos pobres, para fins que não contemplam a função pública da assistência social. Enquanto política de Seguridade Social, a Assistência Social está garantida no Art. 203 e 204 da Constituição Federal de 1988 e deve servir à ampliação de direitos sociais para as pessoas em situação de maior vulnerabilidade socioeconômica.

Enquanto recurso de inclusão social, visualiza-se positivamente o BPC/LOAS para os sujeitos da pesquisa, enquanto contraponto dos efeitos negativos apresentados anteriormente. Dos sujeitos pesquisados, dois possuem o benefício e demonstram com clareza a melhoria na qualidade e projetualidade de vida. 0 benefício tem contribuído para a realização de projetos de trabal ho, com a aquisição de equipamentos para o trabal ho autônomo e para capacitação profissional; o aperfeiçoamento pessoal através de investimento cultural einformações; a inclusão na família por contribuir na renda familiar e a inclusão na rede social através de viagens, lazer, namoros. Em síntese, conforme Faleiros et al. ${ }^{17}$, a renda mínima garantida possibilita 0 acesso ao universo da saúde, da vida, do futuro projetado, da realização dos sonhos, das trocas sociais, da dignidadee da identidade decidadãos.

Adoecimento mental, preconceito e exclusão do trabalho

O preconceito social já é considerado pelo Relatório sobre saúde no mundo ${ }^{18}$ um dos fatores relacionados ao desenvolvimento de sofrimento mental. Conforme Queiroz ${ }^{19}$, no plano psicológico, os indivíduos vítimas de preconceito podem apresentar sentimentos deinferioridade, sinais de melancolia, depressão, ressentimento, insegurança e pessimismo.

Dado a relevância do combate ao preconceito no mundo do trabalho, a Organização Internacional do Trabalho (OIT) publicou, em 1958, a Convenção 111 , que trata da discriminação no emprego e nas profissões. A discriminação nas ocupações foi pauta também na Conferência Internacional do Trabalho, promovida pela OIT em 1998, sendo incorporada na Declaração dos Princípiose Direitos Fundamentais no Trabalho, na América Latina.

0 preconceito e o estigma relacionados às pessoas portadoras de transtorno mental eusuárias de substâncias psicoativas é um fator decisi- vo para a exclusão do mundo do trabalho. Além do estigma da doença mental, é comum haver outros fatores ligados ao preconceito social, dentre eles ser negro, obeso e homossexual.

0 estudo identificou, através dos relatos dos participantes, a experiência do preconceito da seguinte forma: no não acesso a programas de qualificação profissional promovidos pela área da Assistência Social, na perda da confiança eno rebaixamento técnico no ambiente de trabalho referentes às pessoas com dependência a substâncias psicoativas, no autopreconceito, na noção de alguns participantes em ter direitos como argumento para o combate ao preconceito que vivenciam e no impacto do preconceito no mercado de trabalho formal: Trabalhei pouco tempo, adoeci, perdi o emprego por que, digamos assim, a pessoa não vai querer dar trabalho por que tem uma síndrome, digamos, psíquica, por queeu disse pra você anteriormente, qualquer doença é aceita, mas quando se fala da doença queenvolvea razão, o ser, a cabeça, a pessoa simplesmente fica totalmente descrente, desiludido pela sociedade; a pessoa é doida, desabilitado de obter no mundo sócio comum, entende. (A)

\section{Reabilitação psicossocial}

e inclusão social pelo trabalho

A relação entre reabilitação psicossocial e inclusão social pelo trabalho mostrou que os CAPS desenvolvem atividades cotidianas significativas aos participantes da pesquisa por: (a) promover a desospitalização enquanto um evento que por vezes incapacita o sujeito efavorece o estigma social da doença mental; (b) por potencializar asaúde através de atividades terapêuticas, contribuindo para com a autoestima e com o incentivo às qualidades pessoais; (c) pelo sentimento de liberdade; (d) por viabilizar suportesocial através depasse livre de transporte urbano, alimentação, local de descanso, encaminhamentos para outros tratamentos; (e) pelas iniciativas de geração de trabaIho e renda através de cursos, feiras internas que possibilitam consumos por preços acessíveis e de trocas material afetiva, espaço de trabalho para o vendedor autônomo e caixa solidária organizadas por usuários; (f) por estimular a projeção de sonhos, (g) por favorecer as relações interpessoaise (h) por promover o lazer ea convivência. No entanto, quanto à reinserção social através do trabalho, avaliou-se a ausência de projetos capazes de influenciar os condicionantes da exclusão do mundo do trabalho, no qual seencontra boa parte dos usuários frequentes nos CAPS. 
No acompanhamento psicossocial, o estudo identificou a busca subjetiva de autocontrole por parte dos participantes, como condição para voltarem ao trabalho. Destaca-se a adesão ao tratamento medicamentoso, por indicar a possibilidade de remissão do estado clínico. A busca subjetiva de autocontrole dos sintomas faz com que privilegiem o uso racional e seguro dos psicofármacos: A minha saúde eu trato de uma forma muito específica, muito rígi da. Antes de acabar a minha medicação, eu pego a receita. Eu faço uma reserva de medicamento. (A)

\section{Considerações finais}

No decorrer do presenteestudo, observou-seque o trabalho para pessoas com transtorno mental eusuários de substâncias psicoativas possui uma relevância anterior à entrada destes no processo dereabilitação psicossocial. E queo trabal ho ocupa um lugar de destaque na estruturação e/ou desestruturação da vida dos participantes.

Sendo assim, faz-se necessário que a questão do trabal ho seja resgatada pelos Centros deAtenção Psicossocial junto aos usuários, não para procurar uma inserção imediata no mundo do trabalho, mas para valorizar esta dimensão da vida, cujo sentido é construído pela história e pela narrativa do próprio indivíduo.

Os seis eixos de análise resultantes do estudo apresentaram histórias de trabalhos variadas; a complexidade do trabal ho em saúde mental, por implicar em caminhos para a saúde e o adoeci- mento mental; os variados sentidos do trabal ho atribuídos pelos participantes como expressão subjetiva e da condição socioeconômica de cada um; a busca por suporte social através das políticas sociais públicas, em que se verificam tanto os entraves para acesso aos direitos sociais; a importância do recurso financeiro para alçarem projetos de vida e os efeitos do estigma social em torno da loucura.

No processo da atenção psicossocial, faz-se necessário um aprofundamento sobre o papel dos CAPS na articulação entre a clínica com a compreensão do trabalho enquanto um direito $\mathrm{e}$ enquanto uma proposta concreta de reinserção social além do espaço físico dos CAPS. A partir deste estudo e de suas proposições, foi possível fomentar e coordenar iniciativas de geração de trabalho e renda junto à Coordenação de Saúde M ental de Goiânia, com a criação de um grupo de trabalho composto por representantes dos trabalhadores e dos usuários e familiares dos CAPS. Foi elaborado o Plano M unicipal de Saúde M ental e Economia Solidária, o que levou o município a ser contemplado, por duas vezes, com o incentivo financeiro da Portaria $n=1.169$ / $\mathrm{GM}^{20}$, que destina incentivo financeiro para municípios que desenvolvam projetos de inclusão social pelo trabalho, destinados a pessoas portadoras de transtornos mentais e/ou decorrentes do uso de álcool e outras drogas. Criou-se uma associação detrabalho eprodução solidários, que vem promovendo a inclusão social pelo trabal ho junto aos usuários dos serviços públicos e substitutivos de saúde mental.

\section{Colaboradores}

RC Rodrigues trabalhou na concepção teórica, elaboração e redação final dos textos; TPC M arinho trabal hou na elaboração e redação final dos textos e P Amorim participou da orientação da pesquisa como professora da Especialização em Saúde M ental, PUC-GO. 


\section{Referências}

1. Foucault M. História da loucura. 6a ed. São Paulo: Perspectiva; 1972.

2. Minayo MCS. 0 desafio do conhecimento: pesquisa qualitativa em saúde. 2a ed. São Paulo: Hucitec; Rio de Janeiro: Abrasco; 1993.

3. M arx K. M anuscritos econômicos-filosóficos. Lisboa: Editora 70; 1964.

4. Rosa LCS. As condições da família brasileira de baixa renda no provimento de cuidados com o portador de transtorno mental. In: Vasconcelos EM, organizador. Saúde mental e Serviço Social: os desafios da subjetividade e da interdisciplinaridade. São Paulo: Cortez; 2000. p. 263-288.

5. Ferraz AST. Notas sobre a gestão de recursos pessoais dos pacientes em saúde mental e sua contribuição para a qualidade de vida. In: $\mathrm{H}$ arari A, Valentini W, organizadores. A reforma psiquiátrica no cotidiano. São Paulo: Hucitec; 2001. p. 127-136.

6. Silva Filho JF. Trabalho e Saúde M ental. In: Costa I, Holanda AF, M artins F, Tafuri MI, organizadores. VI Conferência Internacional sobre Filosofia, Psiquiatria e Psicologia; 2003; Brasília. Brasília: UnB/ ABRAFIPP; 2003.

7. Jardim SR. Trabalho e Doença Mental. In: Borges LH, organizador. Organização do trabalho e saúde: múltiplas relações. Vitória: EDUFES; 2001. p. 137156.

8. Ramos A, Jardim S, Silva Filho JF. A narrativa na entrevista psiquiátrica: a história de trabalho na construção de diagnóstico em saúde mental do trabalhador. Revista Veredas de Estudos Linguísticos 2007; 1:30-45.

9. Jardim SR. Perícia, Trabalho e Doença Mental. Cadernos IPUB 1997; 3(2): 95-102.

10. Castel R. A ordem psiquiátrica: a idade de ouro do alienismo. 2a ed. Rio de Janeiro: Graal; 1978.

11. Brasil. Decreto o 1.744. Regula o benefício de prestação continuada devido à pessoa portadora de deficiência e ao idoso, de que trata a lei no. 8.742, de 07 de dezembro de 1993, e dá outras providências. Diário Oficial da União 1995; 11 dez.

12. Brasil. Lei $\mathrm{n}$ 0 8.742. Dispõe sobre a organização da Assistência Social e dá outras providências. Diário Oficial da União 1993; 8 dez.
13. Brasil. M edida provisória $n$ 0 1.473-34. Altera a redação nos dispositivos da lei no. 8.742 de 07/12/ 1993, que dispõe sobre a organização da Assistência Social, e dá outras providências. Diário Oficial da União 1997; 11 ago.

14. Brasil. Lei no 9.720. Dá nova redação a dispositivos da Lei $n$ ㅇ. 8.742, de 7 de dezembro de 1993, que dispõe sobre a organização da Assistência Social, e dá outras providências. Diário Oficial da União 1998; 1 dez.

15. Brunca B. [comunicação oral]. In: Seminário Nacional "Banalização da Interdição Judicial no Brasil: uma violência contra a democracia e os direitos humanos"; 2005; Brasília.

16. Brasil. Decreto no 5.699. Altera dispositivos do Decreto $n=3.048 / 99$ e dispõe sobre o protocolo de benefícios por incapacidade pela empresa, por meio da internet, restituição de importâncias recebidas indevidamente, decisões das Juntas de Recursos do Conselho de Recurso da Previdência Social, exigência do termo de curatela e dá outras providências. Diário Oficial da União 2006; 14 fev.

17. Faleiros ETS, Alves MASC, Diniz SP. A prestação continuada como recurso de inclusão social. Revista da Saúde 2001; 2(2):17-18.

18. Organização Mundial de Saúde. Relatório sobre saúde no mundo 2001 - Saúde mental: nova concepção, nova esperança. Genebra: OM S; 2001.

19. Queiroz RS. Não vi e não gostei - o fenômeno do preconceito. 5a ed. São Paulo: Moderna; 1995.

20. Brasil. Portaria no 1.169. Destina incentivo financeiro para municípios que desenvolvam projetos de inclusão social pelo trabalho, destinados às pessoas portadoras de transtornos mentais e/ou de transtornos decorrentes do uso de álcool e outras drogas, e dá outras providências. Diário Oficial da União 2005; 12 ago.

Artigo apresentado em 26/01/2008

Aprovado em 29/10/2008

Versão final apresentada em 13/01/2009 